\title{
"Chemometrics" applied to the optimization of the preparation of hydrotropes for detergents starting from BTX fraction of natural gas
}

\author{
A. Kamoun and M. Châabouni \\ Laboratoire de Chimie Industrielle, École Nationale d'Ingénieurs de Sfax, BP W 3038, Sfax, Tunisia
}

\begin{abstract}
Manufacturers of cleaning products use hydrotropes to increase the solubility of surfactants in concentrated liquid detergents. In contrast to benzenesulfonate, alkylbenzenesulfonates with short chains $(n<4)$ are used as hydrotropes. In this paper, we present the results obtained from the preparation of toluenesulfonic and xylenesulfonic acids by selective sulfonation of toluene and xylenes present in the BTX fraction (benzene, toluene, xylenes) of the Tunisian natural gas MISKAR deposit. Chemometrics were applied to determine the optimal experimental conditions for the selective sulfonation of toluene and xylenes, we use a $2_{\mathrm{IV}}^{6-2}$ fractional factorial design in addition to several analytical methods (GC, HPLC, FTIR...). These conditions were found to be: the use of concentrated sulfuric acid as sulfonating agent, the azeotropic elimination of water during the reaction, a temperature of $110{ }^{\circ} \mathrm{C}$, a duration of 9 hours and a molar ratio of sulfuric acid to toluene plus xylenes of 0.8. The application of all of these experimental conditions gives an aqueous phase with a composition that can be used very effectively as hydrotrope agent in liquid detergents. This conclusion was the outcome from comparing the effect of our product on the clear point of a typical premium formulation of a liquid detergent to that of sodium xylenesulfonates, the most important hydrotrope for light duty liquids.
\end{abstract}

These products are prepared by reacting the corresponding aromatic hydrocarbons with sulfonating agents such as sulfuric acid, oleum, sulfur trioxide or chlorosulfonic acid, then by neutralizing the corresponding sulfonic acids.

We have intended to prepare hydrotrope agents by sulfonation of the by-product of natural gas commonly known as BTX fraction (Benzene, Toluene, and Xylenes). Unfortunately, sodium benzenesulfonate (SBS) has no hydrotropic power and can lead to cloudy liquid detergent [5]. We have, consequently, tried to determine the experimental conditions permitting to sulfonate selectively the toluene and the xylenes to the detriment of benzene.

The individual behavior of benzene, toluene and xylenes in the presence of sulfonating agents such as sulfuric acid or $\mathrm{SO}_{3}$ are widely documented. The work of Cerfontain et al. [6-12] carried out over many years on sulfonation kinetic and isomer distribution, is still the major reference on this subject. A large body of literature about the methods and processes for the manufacture of aromatic sulfonic acids can be found in the patent literature [4,13-16]. All the data obtained in these cases are useful but there is no experimental information that assures their extrapolability to the mixtures of aromatic hydrocarbons.

Experiments with pairs of these aromatic hydrocarbons have only been conducted with benzene and toluene. The competitive sulfonation of toluene and benzene has been studied by Cerfontain et al. [11,12] and El Homsi et al. $[17,18]$ using $\mathrm{SO}_{3}$ as sulfonating agent. These studies were undertaken at low temperatures $\left(-20,+20{ }^{\circ} \mathrm{C}\right)$ in order to find the most selective solvents, as regards the isomer distribution and the relative reactivity of toluene and benzene.

To our knowledge, no information has been published about the behavior of mixtures of benzene, toluene and xylenes in the presence of sulfonating agents.

The purpose of this paper is to determine suitable experimental conditions for selective sulfonation of toluene and xylenes present in the BTX fraction of the natural gas of MISKAR- Tunisia (53\% benzene, $25 \%$ toluene, $10 \%$ xylenes, $1 \%$ ethylbenzene and $11 \%$ non aromatic hydrocarbons). The products obtained are found to be very effective hydrotropes for concentrated liquid detergents. 


\section{Methodology}

Our search for the best conditions was based on chemometric techniques. This chemical discipline uses statistical methods to select optimal measurement procedures and experiments and to provide maximum chemical information by evaluating analytical data [19].

In this work chemometrics are applied to determine the optimal experimental conditions for the selective sulfonation of toluene and xylenes in an optimal way by carefully planning experiments and using in each case the appropriate analytical methods and measurements.

To this end, several analytical methods as HPLC, GC and, FTIR have been performed to identify and to measure quantitatively the components of the reaction products; this is achieved using a designed experiment to study the sulfonation reactions. The fractional factorial designs are among the most widely used types of designs for product and process improvement [14-20]. Thus, a two-level fractional factorial design $26-2$ was applied to determine the direct influence of six experimental variables as well as their possible interaction effects on the selectivity of the sulfonation reaction. The experimental results obtained were treated by the computer program NEMROD [25]. The following paragraph is devoted to briefly remind some principles governing the construction and analysis of this experimental design.

\section{Basic definitions}

In a two level factorial design $2^{k}$, all possible combinations of the levels of $k$ factors are investigated. This permits to determine the influence of the variation of each factor and the effects of all their mutual interactions on the response. In a fractional factorial design, we assume that interaction effects between three or more factors are negligible; useful information on the main effects and low order interactions may be obtained, thus, by running only a fraction of the complete factorial design.

In a $2^{6-2}$ fractional factorial design, six variables (factors) are studied each at two levels. The effects of two variables (extra variables) are confounded with two high order interactions between the four other variables (basic variables).

In this work, the $2^{6-2}$ fractional factorial design is obtained by writing down the complete $2^{4}$ factorial as the basic design (with the four variables $X_{1}, X_{2}, X_{3}$ and $X_{4}$ ) and then equating factors $X_{5}$ and $X_{6}$ to the $X_{1} X_{2} X_{4}$ and $X_{2} X_{3} X_{4}$ interactions respectively.

\section{Effects and aliases}

The last conditions allow us to identify the independent generators (1) and the corresponding complete defining relation (2) which is the set of all columns that correspond to the identity column I:

$$
\begin{gathered}
I=1245=2346 \\
I=1245=2346=1356
\end{gathered}
$$

From this set of generators, it is possible to develop the complete alias structure for this design and to select fifteen effects and their aliases which may be estimated from the experimental data as shown in table I (the four factor and higher interactions are neglected). Consequently, the design is of resolution IV because every main effect is aliased with a three-factor interaction and every two-factor interaction is aliased with at least another two-factor interaction. We can reasonably assume that three-factor interactions are negligible and would expect this design to provide excellent information concerning the main effects.

\begin{tabular}{ll}
\hline Table I. Effects and their aliases. \\
\hline$l_{1}=b_{1}+b_{245}+b_{356}$ & $I_{14}=b_{14}+b_{25}$ \\
$I_{2}=b_{2}+b_{145}+b_{346}$ & $I_{23}=b_{23}+b_{46}$ \\
$I_{3}=b_{3}+b_{246}+b_{156}$ & $I_{24}=b_{24}+b_{15}+b_{36}$ \\
$I_{4}=b_{4}+b_{125}+b_{236}$ & $I_{34}=b_{34}+b_{26}$ \\
$I_{5}=b_{5}+b_{124}+b_{136}$ & $I_{16}=b_{16}+b_{35}$ \\
$I_{6}=b_{6}+b_{234}+b_{135}$ & $I_{123}=b_{123}+b_{345}+b_{146}+b_{256}$ \\
$I_{12}=b_{12}+b_{45}$ & $I_{134}=b_{134}+b_{235}+b_{126}+b_{456}$ \\
$I_{13}=b_{13}+b_{56}$ & \\
\hline
\end{tabular}

\section{Estimates and significance of the effects of the factors}

To simplify the calculations, coded variables $X_{j}$ are used instead of natural variables $u_{j}$. The range of variation of each $u_{j}$ is transformed into a variation of $X_{j}$ between -1 and +1 [20-22].

The main effect $b_{j}$ of a factor $X_{j}$ and the interaction effect $b_{j k}$ of a two factor interaction $X_{j} X_{k}$ are calculated using equations (3) and (4) [20-24]:

$$
\begin{gathered}
b_{j}=\frac{\sum_{i} y_{i} X_{i j}}{16} \\
b_{j k}=\frac{\sum_{i} y_{i} X_{i j} X_{i k}}{16}
\end{gathered}
$$

where $y_{i}$ and $X_{i j}$ represent respectively the response of interest and the reduced value of the level of the factor $j$ in the run $i$.

The estimate of the influence of each variable on the systematic variation has a probability distribution due to the experimental error. In many cases a useful estimate of the experimental error (with sufficient degrees of freedom) is not available. In such cases, the significance of the estimated parameters can be assessed from a normal probability plot [20-22,25,26]. 
The procedure is to construct a normal probability plot of the effects, which is a graph of the cumulative distribution of the ordered effects on a normal probability paper. All of the effects that lie along the line are negligible, whereas, the large effects are far from the line.

In this work, both an analysis of variance and a normal probability plot assess the significance of the estimated parameters.

$$
\mathrm{CH}_{3} \longrightarrow \mathrm{CH}_{3} \longrightarrow \mathrm{H}_{2} \mathrm{SO}_{4} \longrightarrow \mathrm{SO}_{3} \mathrm{H}
$$

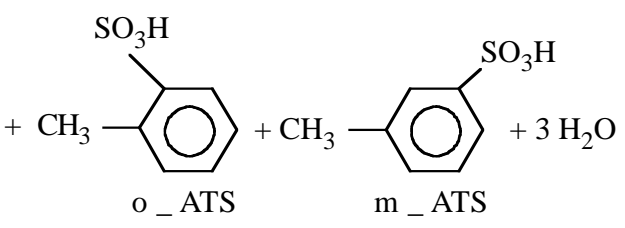

\section{Experimental section}

\section{Apparatus and reaction conditions}

The sulfonation of aromatic compounds is a process that presents very interesting theoretical characteristics and practical difficulties. For example, the sulfonation of toluene leads to the three isomers ortho, para and meta-toluenesulfonic acids (the m-isomer is formed in very low amount). The global equation can be written as follows:

The sulfonation reaction of the "BTX mixture" of the natural gas - MISKAR - Tunisia, was carried out in a batch reactor of $1000 \mathrm{~mL}$ placed in an oil bath and equipped with an agitator and a thermometer. One neck of the reactor was fitted to a $500 \mathrm{~mL}$ graduated separatory funnel for addition of the sulfonating agent $\left(\mathrm{H}_{2} \mathrm{SO}_{4} 97 \%\right.$ or oleum $\left.10 \% \mathrm{SO}_{3}\right)$ at a known rate. A second neck of the reactor was fitted with a condenser for refluxing vapours or with a Dean and Stark apparatus filled with "BTX mixture" to azeotropically remove the water produced. The reaction was conducted by adding the sulfonating agent to the mixture, which had previously been brought to the reaction temperature. Vigorous agitation was used throughout the reaction, while the temperature was maintained constant at $\pm 0,5^{\circ} \mathrm{C}$. At the end of the reaction time, the resulting mixture was treated with a fixed volume of water to facilitate the separation of organic phase (the upper layer) and sulfuric phase (the lower layer). The recovery of organic and inorganic material was quantitative.

\section{Analytical methods}

\section{Analyses of the BTX mixture}

Analyses of the raw material (BTX fraction of natural gas) were carried out by gas chromatography on a Shimadzu GC-9A apparatus equipped with a flame ionization detector. Quantitative analyses of benzene, toluene and xylenes were performed with external standard procedure. Calibration factors were determined by using six standards mixtures of these three aromatic hydrocarbons. The use of the internal standard method has been attempted unsuccessfully particularly with diethylether, isopropanol or ethanol as internal standard.

The external standard method was also applied to analyze the BTX mixture of the Dean and Stark apparatus after reaction.

\section{Analyses of the organic phase}

After separation and weighing, the organic phase was also analysed by gas chromatography in order to determine the quantities of the unreacted reagents.

\section{Analyses of the aqueous phase}

Analyses of the aqueous phase were performed to determine the proportions of benzenesulfonic acid (BSA), toluenesulfonic acids (TSA), xylenesulfonic acids (XSA) and unreacted sulfuric acid (SA).

Ion exchange high performance liquid chromatography was used to determine the amounts of BSA, TSA and XSA after neutralization. Chromatograms were obtained with a Shimadzu HIC chromatograph equipped with an UV detector. Calibrations were achieved with the standard addition method and the internal standard method using sodium phthalate as standard. All calibration curves had a correlation coefficient of 0.99 .

The amount of unreacted sulfuric acid was measured as free sulfates by volumetric titration in a water-ketone medium using a lead solution as titrating agent and dithizone as indicator.

Qualitative analyses of the neutralized and dried aqueous phase were performed by FTIR spectroscopy.

\section{Results and discussion}

Although the sulfonation procedure was simple, evaluation of the results obtained from preliminary experiments carried out on synthetic mixtures of benzene and toluene, indicated that several variables could influence the yield and the selectivity of the sulfonation reaction. Some of these variables were previously found [6-12,14-18,27-29] to have a significant effect on the sulfonation of toluene alone or benzene alone. 
Table II. Variables and experimental domain.

\begin{tabular}{lcc} 
Variables & Level $(-)$ & Level (+) \\
$X_{1}$ : Reaction time $(\boldsymbol{D})$. & $5^{\mathrm{H}} \mathrm{g}^{\mathrm{H}}$ \\
$X_{2}$ : Sulfonating agent $(\boldsymbol{C})$. & $97 \% \mathrm{H}_{2} \mathrm{SO}_{4}$ & $\left.\mathrm{Oleum}^{(10} \% \mathrm{SO}_{3}\right)$ \\
$X_{3}$ : Temperature of the oil bath $(\boldsymbol{T})$. & $95{ }^{\circ} \mathrm{C}$ & $110{ }^{\circ} \mathrm{C}$ \\
$X_{4}$ : Azeotropic elimination of water $(\boldsymbol{E})$. & Without elimination & With elimination \\
$X_{5}$ : Time over which the sulfonating agent is added $(\boldsymbol{t})$. & 10 min & 30 min \\
$X_{6}$ : Molar ratio of sulfuric acid to (toluene + xylenes) $(\boldsymbol{R})$ & 0.8 & 1.2 \\
\hline
\end{tabular}

In this work, the purpose is to indicate which variables have a significant effect on the selectivity of the sulfonation reaction of the BTX fraction of the natural gas. Six variables were investigated and a fractional factorial design was applied. The variables and the range of their variations are given in table II. These ranges are chosen taking into account the yields of the sulfonation reaction obtained with the synthetic mixtures of toluene and benzene.

Sixteen experiments were run to determine how the six variables influenced the following responses:

- $y_{B}$ : the percentage of benzene sulfonation;

- $y_{T}$ : the percentage of toluene sulfonation;

- $y_{X}$ : the percentage of xylenes sulfonation;

- $S=y_{(T+X) / B}$ : the ratio of the percentage of toluene and xylenes sulfonation to the percentage of benzene sul- fonation. This response is used to study the selectivity of the reaction.

\section{General remarks}

The product of the sulfonation reaction of the BTX fraction separates, at room temperature, in two phases; the aqueous phase, the heaviest, is a viscous liquid with a clear brown color, the organic phase, on the other hand, is characterised by a pale yellow colour.

Gas chromatograms of the organic phase and ion exchange chromatograms of the aqueous phase provide an adequate resolution to allow accurate quantitative analyses.

Gas chromatogram of the organic phase compared to that of BTX, the raw material (Fig. 1) proved that this phase contains mainly residual BTX mixture.
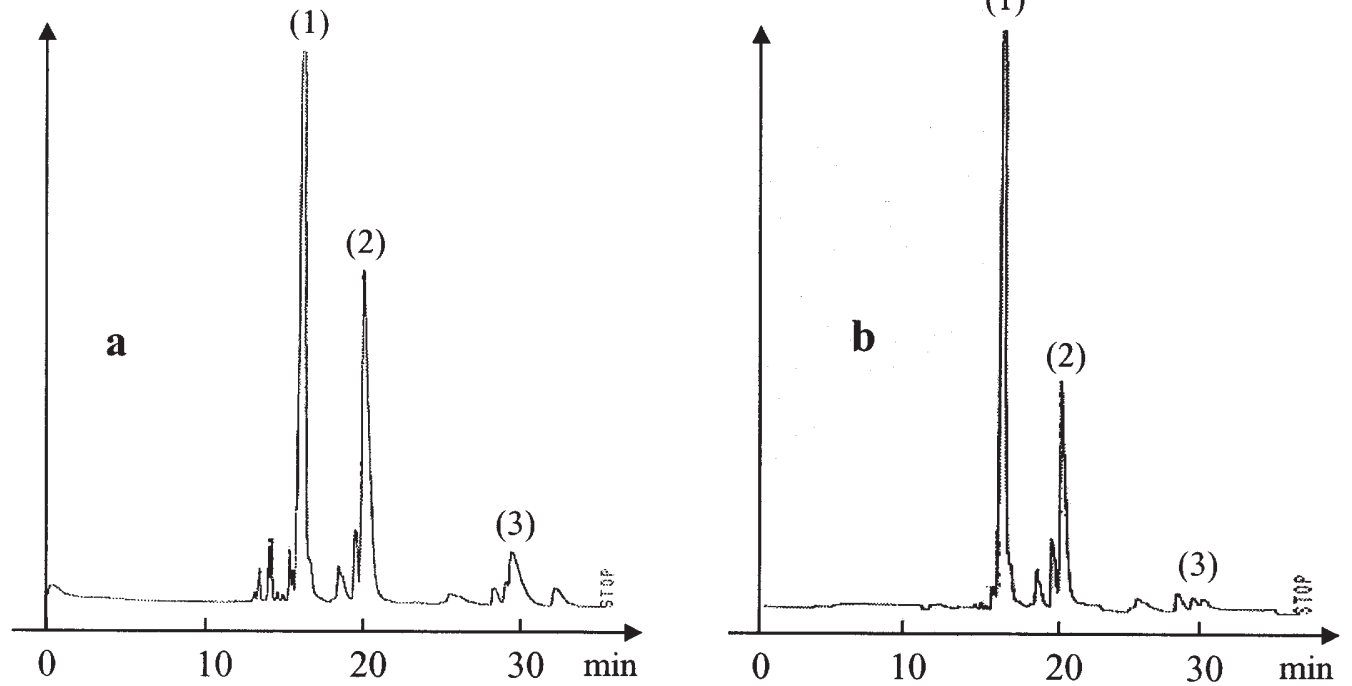

Figure 1. Gas chromatograms of (a) BTX fraction of natural gas; (b) residual organic phase.

Apparatus: Shimadzu, Column: bonded phase CBP1 (non-polar), $L=50 \mathrm{~m}$; Temperature: $100{ }^{\circ} \mathrm{C}$; Detector: FID; Injection of $0.5 \mu$ l. (1) Benzene, (2) Toluene, (3) Xylenes. 

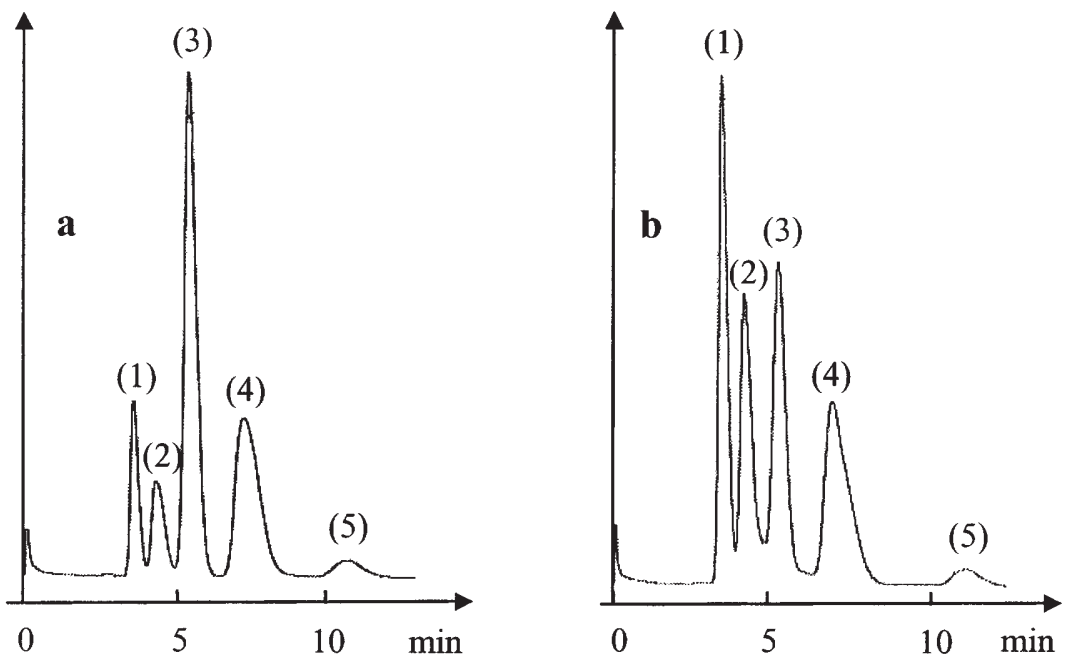

Figure 2. Ion exchange chromatograms of (a) neutralized aqueous phase; (b) reference solution.

Apparatus: Shimadzu HIC, Column: Shim pack IC A1 (quaternary ammonium resin), $L=10 \mathrm{~cm}$, ID $4.6 \mathrm{~mm}$; Temperature: $40{ }^{\circ} \mathrm{C}$; Mobile phase: $\mathrm{NaClO}_{4} \quad 6 \quad \mathrm{mM}$ in phosphate buffer $\mathrm{NaH}_{2} \mathrm{PO}_{4} / \mathrm{Na}_{2} \mathrm{HPO}_{4}$, Flow rate: $0.6 \mathrm{~mL} / \mathrm{min}$; Detection: UV, $\lambda=254 \mathrm{~nm}$; injection of $20 \mu \mathrm{L}$. (1) Standard: Sodium phthalate, (2) SBS, (3 and 5) STS and (4) SXS.

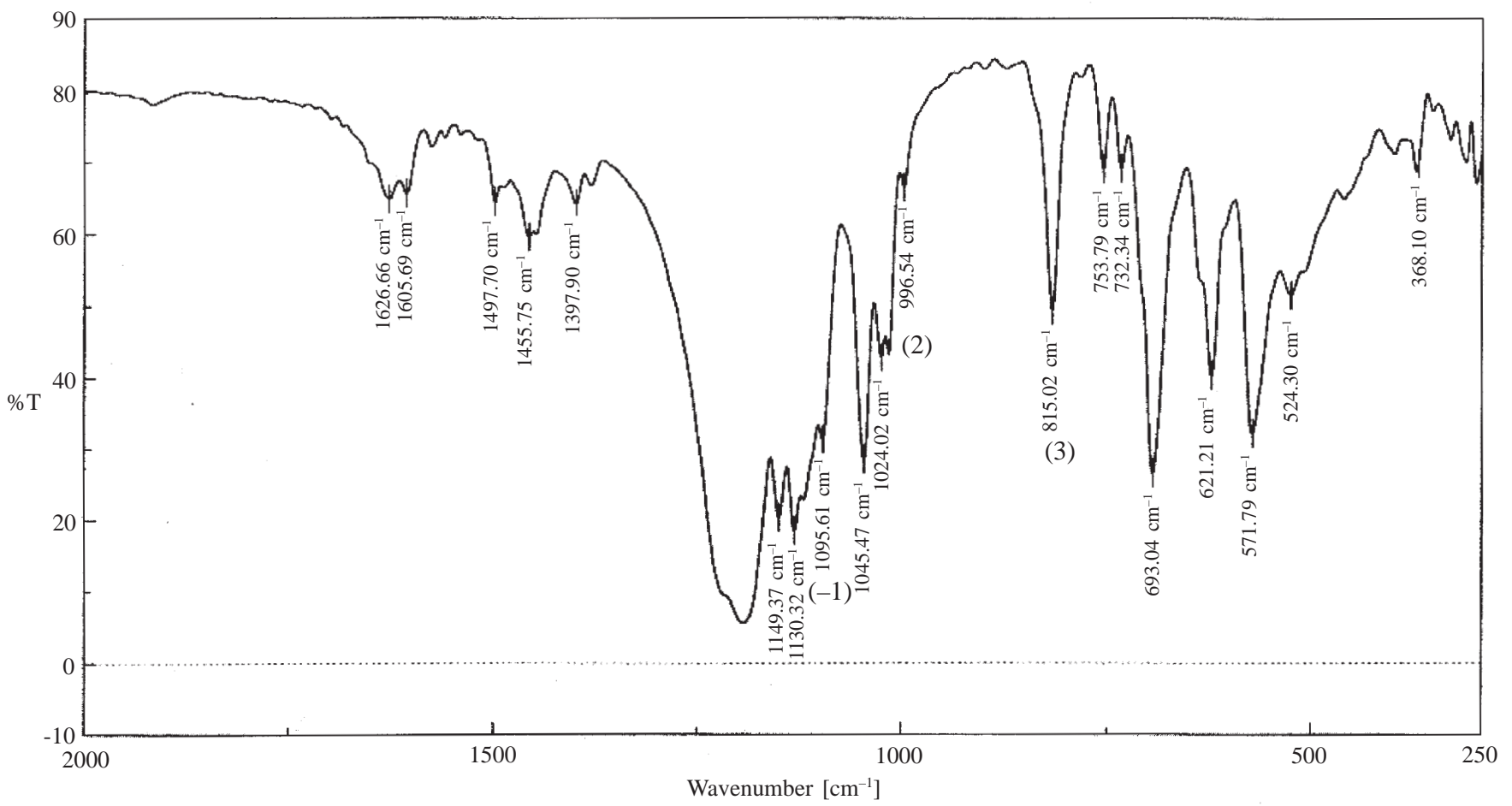

Figure 3. FTIR spectrum in KBr of a dried neutralized sample of BTXS 14.

(1) SXS, (2) SBS, (3) SXS and STS

Figure 2 illustrates a typical ion exchange chromatogram of the neutralised and dried aqueous phase. It indicates that this phase contains SBS, STS and, SXS.

In addition, we show that FTIR spectrometry is a useful method to qualitatively analyse the reaction product. Figure 3 shows an infrared spectrum of a dried neutralised sample of the aqueous phase. The vibration bands of average intensity situated at 1120 and $630 \mathrm{~cm}^{-1}$ are characteristic of free sulfate ions [28]. The bands detected at 1096, 996 and, $815 \mathrm{~cm}^{-1}$ are specific respectively to SXS, SBS and, STS or SXS.

The yields of benzenesulfonic, toluenesulfonic and xylenesulfonic acids can be determined directly from the aqueous phase by ionic HPLC after neutralisation and indirectly 
Table III. Experimental design and responses.

\begin{tabular}{|c|c|c|c|c|c|c|c|c|c|c|}
\hline Run & $\begin{array}{c}D \\
\left(X_{1}\right)\end{array}$ & $\begin{array}{c}C \\
\left(X_{2}\right)\end{array}$ & $\begin{array}{c}T \\
\left(X_{3}\right)\end{array}$ & $\begin{array}{l}E^{a} \\
\left(X_{4}\right)\end{array}$ & $\begin{array}{c}t \\
\left(X_{5}\right)\end{array}$ & $\begin{array}{c}R \\
\left(X_{6}\right)\end{array}$ & $\begin{array}{c}y_{B} \\
(\%)\end{array}$ & $\begin{array}{c}y_{T} \\
(\%)\end{array}$ & $\begin{array}{c}y_{x} \\
(\%)\end{array}$ & $S$ \\
\hline 1 & $5^{\mathrm{H}}$ & $97 \% \mathrm{H}_{2} \mathrm{SO}_{4}$ & $95^{\circ}$ & $(-)$ & $10 \min$ & 0.8 & 3.20 & 28.08 & 64.27 & 11.76 \\
\hline 2 & $9^{H}$ & $97 \% \mathrm{H}_{2} \mathrm{SO}_{4}$ & $95^{\circ}$ & $(-)$ & $30 \mathrm{~min}$ & 0.8 & 3.12 & 29.26 & 66.47 & 12.55 \\
\hline 3 & $5^{\mathrm{H}}$ & Oleum & $95^{\circ}$ & $(-)$ & $30 \mathrm{~min}$ & 1.2 & 7.78 & 54.08 & 81.44 & 7.89 \\
\hline 4 & $9^{H}$ & Oleum & $95^{\circ}$ & $(-)$ & $10 \min$ & 1.2 & 8.28 & 62.08 & 83.93 & 8.20 \\
\hline 5 & $5^{\mathrm{H}}$ & $97 \% \mathrm{H}_{2} \mathrm{SO}_{4}$ & $110^{\circ}$ & $(-)$ & $10 \min$ & 1.2 & 4.49 & 48.33 & 75.08 & 12.35 \\
\hline 6 & $9^{H}$ & $97 \% \mathrm{H}_{2} \mathrm{SO}_{4}$ & $110^{\circ}$ & $(-)$ & $30 \mathrm{~min}$ & 1.2 & 4.39 & 54.91 & 79.18 & 13.98 \\
\hline 7 & $5^{\mathrm{H}}$ & Oleum & $110^{\circ}$ & $(-)$ & $30 \mathrm{~min}$ & 0.8 & 5.83 & 31.86 & 70.94 & 7.25 \\
\hline 8 & $9^{H}$ & Oleum & $110^{\circ}$ & $(-)$ & $10 \mathrm{~min}$ & 0.8 & 4.80 & 39.37 & 73.69 & 10.10 \\
\hline 9 & $5^{\mathrm{H}}$ & $97 \% \mathrm{H}_{2} \mathrm{SO}_{4}$ & $95^{\circ}$ & $(+)$ & $30 \mathrm{~min}$ & 1.2 & 4.67 & 54.00 & 80.55 & 13.06 \\
\hline 10 & $9^{H}$ & $97 \% \mathrm{H}_{2} \mathrm{SO}_{4}$ & $95^{\circ}$ & $(+)$ & $10 \min$ & 1.2 & 5.13 & 63.25 & 83.63 & 13.40 \\
\hline 11 & $5^{\mathrm{H}}$ & Oleum & $95^{\circ}$ & $(+)$ & $10 \min$ & 0.8 & 3.84 & 36.48 & 74.13 & 12.10 \\
\hline 12 & $9^{H}$ & Oleum & $95^{\circ}$ & $(+)$ & $30 \mathrm{~min}$ & 0.8 & 5.77 & 42.47 & 75.80 & 8.91 \\
\hline 13 & $5^{\mathrm{H}}$ & $97 \% \mathrm{H}_{2} \mathrm{SO}_{4}$ & $110^{\circ}$ & $(+)$ & $30 \mathrm{~min}$ & 0.8 & 3.41 & 35.93 & 74.96 & 13.65 \\
\hline 14 & $9^{H}$ & $97 \% \mathrm{H}_{2} \mathrm{SO}_{4}$ & $110^{\circ}$ & $(+)$ & $10 \min$ & 0.8 & 3.61 & 49.21 & 82.49 & 16.10 \\
\hline 15 & $5^{\mathrm{H}}$ & Oleum & $110^{\circ}$ & $(+)$ & $10 \min$ & 1.2 & 6.57 & 67.91 & 86.64 & 11.09 \\
\hline 16 & $9^{H}$ & Oleum & $110^{\circ}$ & $(+)$ & $30 \mathrm{~min}$ & 1.2 & 8.03 & 75.57 & 89.19 & 9.86 \\
\hline
\end{tabular}

a $E(-)$ and $E(+)$ : Without and with azeotropic elimination of water respectively.

from the organic phase by gas chromatography. The results obtained are very close and confirmed by the volumetric analysis of free sulfates.

\section{The fractional factorial design $2_{\mathrm{IV}}^{6-2}$}

\section{Experimental design and estimate of effects}

The experimental design and the measured responses are summarised in table III.

From the obtained results, estimates of the main effects and aliases of confounded two-variable interaction effects can be computed [25]. These values are shown on table IV, where $b_{0}$ is the average. The interaction effects between three and four variables are small as compared to main effects or two-variable interaction effects. This may indicate that no important variable has been omitted in this study.

\section{Significance of the effects}

The significance of the estimated parameters of each response is assessed from a Normal probability plot. Figure 4 shows the normal probability plot of the estimated effects of the four responses studied. For benzene, two linear coefficient $b_{2}$ and $b_{6}$ deviate from the normal probability line. It can therefore be concluded that these main effects are the only effects distinguishable from noise and that the range of variation of $X_{1}, X_{3}, X_{4}$ and $X_{5}$ in the experiments does not have any influence on the sulfonation yield of benzene.

For toluene, four linear coefficients $b_{1}, b_{2}, b_{3}, b_{4}, b_{6}$ and one alias " $b_{34}+b_{26}$ " deviate from the normal probability line.
Table IV. Estimated effects.

\begin{tabular}{lrrrr}
\hline Effects & \multicolumn{1}{c}{$y_{B}$} & \multicolumn{1}{c}{$y_{T}$} & \multicolumn{1}{c}{$y_{X}$} & \multicolumn{1}{c}{$S$} \\
\hline$l_{0}=b_{0}$ & 5.18 & 48.30 & 77.65 & 11.39 \\
$l_{1}=b_{1}+b_{245}+b_{356}$ & 0.21 & 3.72 & 1.65 & 0.25 \\
$l_{2}=b_{2}+b_{145}+b_{346}$ & 1.18 & 2.93 & 1.82 & -1.97 \\
$l_{3}=b_{3}+b_{246}+b_{156}$ & -0.04 & 2.09 & 1.37 & 0.41 \\
$l_{4}=b_{4}+b_{125}+b_{236}$ & -0.05 & 4.80 & 3.28 & 0.88 \\
$I_{5}=b_{5}+b_{124}+b_{136}$ & 0.19 & -1.04 & -0.33 & -0.50 \\
$l_{6}=b_{6}+b_{234}+b_{135}$ & 0.98 & 11.72 & 4.81 & -0.16 \\
$l_{12}=b_{12}+b_{45}$ & 0.15 & -0.07 & -0.47 & -0.41 \\
$l_{13}=b_{13}+b_{56}$ & -0.14 & 0.66 & 0.47 & 0.47 \\
$l_{14}=b_{14}+b_{25}$ & 0.30 & 0.81 & 0.21 & -0.45 \\
$l_{23}=b_{23}+b_{46}$ & -0.01 & 0.36 & -0.73 & -0.26 \\
$l_{24}=b_{24}+b_{15}+b_{36}$ & -0.26 & -0.42 & -1.31 & 0.19 \\
$l_{34}=b_{34}+b_{26}$ & 0.32 & 1.96 & 1.02 & 0.00 \\
$l_{16}=b_{16}+b_{35}$ & 0.08 & 0.22 & -0.12 & -0.12 \\
$l_{123}=b_{123}+b_{345}+b_{146}+b_{256}$ & -0.11 & -0.52 & -0.32 & 0.10 \\
$l_{134}=b_{134}+b_{235}+b_{126}+b_{456}$ & 0.05 & 0.05 & 0.20 & 0.04 \\
\end{tabular}

Similar results are obtained for xylenes but two aliases " $b_{34}+b_{26}$ " and " $b_{24}+b_{15}+b_{36}$ " are found to be significant; this is, however, difficult to confirm with the normal probability plot. A clearer plot (half-normal probability plot $[20,21])$ can be obtained if the absolute values of the estimated effects are plotted as shown in figure 5. 
Probability

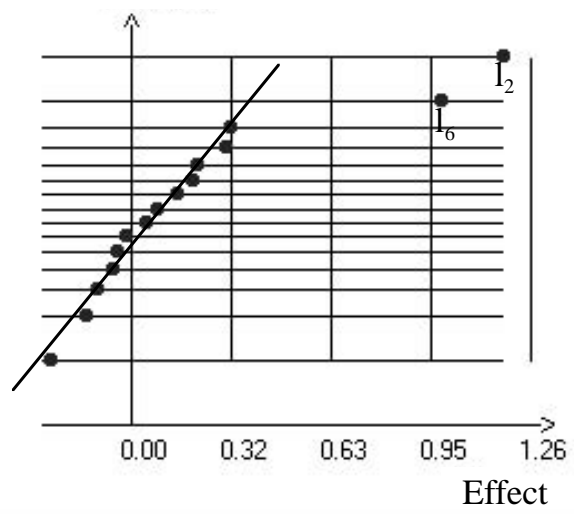

Probability

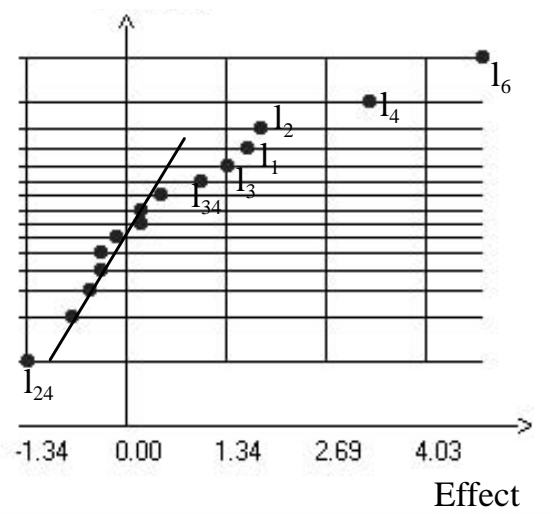

Probability

(2)

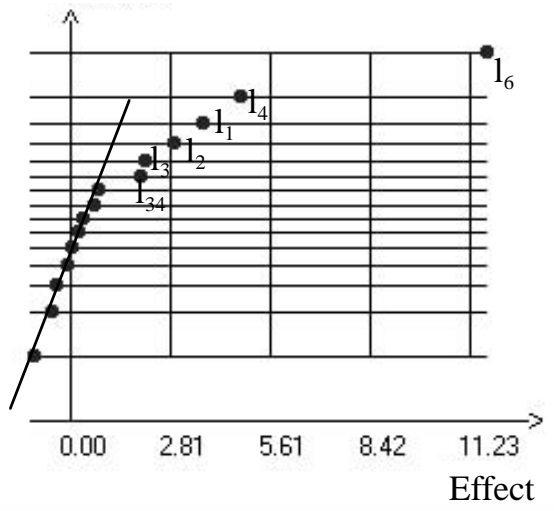

Probability

(4)

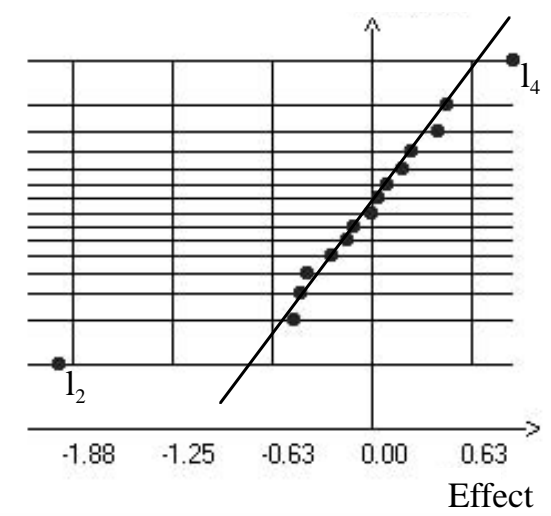

Figure 4. Normal probability plot of the estimated effects of:

(1) $y_{B}$ : percentage of benzene sulfonation;

(2) $y_{T}$ : percentage of toluene sulfonation;

(3) $y_{X}$ : percentage of xylenes sulfonation;

(4) $S=y_{(T+X) / B}$ : the ratio of the percentage of toluene and xylenes sulfonation to the percentage of benzene sulfonation.

Probability

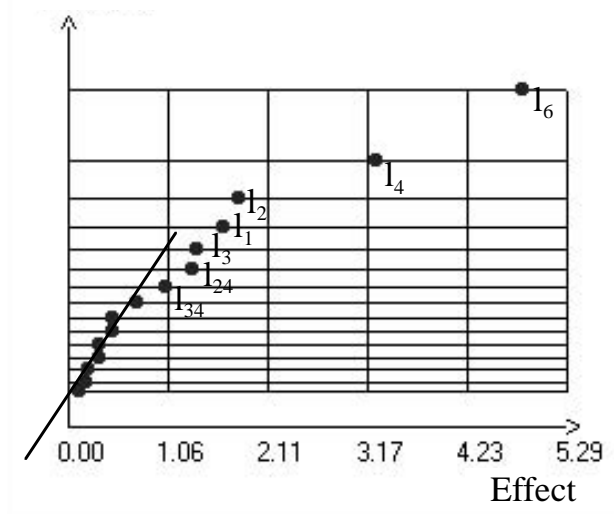

Figure 5. Half-normal probability plot of the estimated effects of $y_{x}$.
For selectivity, only the effects of the variables $X_{2}$ and $X_{4}$ are significant.

This statistical study agrees with an analysis of variance based on a determination of the experimental error by duplication of two experiments carried out as indicated in table V. These conditions allow us to estimate the sum of squares of pure error for each response with two degrees of freedom. Table VI summarises the results of the analysis of variance based on the Fisher test, (comparison of $F$ ratios to critical $\left.F_{0.05}(1,2)\right)[21,22]$.

\section{Discussion}

\section{Experimental design}

In this study, the results are very simple and the information can be obtained directly from the values of the effects. It is 
Table V. Replicated runs.

\begin{tabular}{|c|c|c|c|c|c|c|c|c|c|c|}
\hline Run & $\begin{array}{c}D \\
\left(X_{1}=0\right)\end{array}$ & $\begin{array}{c}C \\
\left(X_{2}=0\right)\end{array}$ & $\begin{array}{c}T \\
\left(X_{3}=0\right)\end{array}$ & $\begin{array}{c}E^{a} \\
\left(X_{4}= \pm 1\right)\end{array}$ & $\begin{array}{c}t \\
\left(X_{5}=0\right)\end{array}$ & $\begin{array}{c}R \\
\left(X_{6}=0\right)\end{array}$ & $\begin{array}{l}y_{B} \\
(\%)\end{array}$ & $\begin{array}{c}y_{T} \\
(\%)\end{array}$ & $\begin{array}{l}y_{x} \\
(\%)\end{array}$ & $S$ \\
\hline 17 & $7^{\mathrm{H}}$ & Oleum $\left(3.5 \% \mathrm{SO}_{3}\right)$ & $102.5^{\circ}$ & $(-)$ & $20 \min$ & 1.0 & 6.17 & 43.18 & 75.82 & 8.80 \\
\hline $17^{\prime}$ & $7^{\mathrm{H}}$ & Oleum $\left(3.5 \% \mathrm{SO}_{3}\right)$ & $102.5^{\circ}$ & $(-)$ & $20 \min$ & 1.0 & 6.71 & 45.01 & 74.19 & 8.03 \\
\hline 18 & $7^{\mathrm{H}}$ & Oleum $\left(3.5 \% \mathrm{SO}_{3}\right)$ & $102.5^{\circ}$ & $(+)$ & $20 \min$ & 1.0 & 5.97 & 53.69 & 82.04 & 10.47 \\
\hline $18^{\prime}$ & $7^{\mathrm{H}}$ & Oleum $\left(3.5 \% \mathrm{SO}_{3}\right)$ & $102.5^{\circ}$ & $(+)$ & $20 \min$ & 1.0 & 5.21 & 54.71 & 79.91 & 11.87 \\
\hline
\end{tabular}

${ }^{a} E(-)$ and $E(+)$ : Without and with azeotropic elimination of water respectively

Table VI. Significance of effects by ANOVA.

\begin{tabular}{|c|c|c|c|c|c|c|c|c|}
\hline \multirow[b]{2}{*}{ Effects } & \multicolumn{2}{|c|}{$y_{B}$} & \multicolumn{2}{|c|}{$y_{T}$} & \multicolumn{2}{|c|}{$y_{x}$} & \multicolumn{2}{|c|}{$S$} \\
\hline & $F$ cal. $^{a}$ & Test $t^{b}$ & F cal. ${ }^{a}$ & Test $^{b}$ & $F$ cal. $^{a}$ & Test $t^{b}$ & $F$ cal. $^{a}$ & Test $^{b}$ \\
\hline$l_{1}=b_{1}+b_{245}+b_{356}$ & 3.21 & & 201.30 & ** & 24.17 & * & 1.53 & \\
\hline$I_{2}=b_{2}+b_{145}+b_{346}$ & 102.52 & ** & 125.02 & ** & 29.49 & * & 96.86 & * \\
\hline$I_{3}=b_{3}+b_{246}+b_{156}$ & 0.13 & & 63.50 & * & 16.74 & & 4.15 & \\
\hline$I_{4}=b_{4}+b_{125}+b_{236}$ & 0.21 & & 336.38 & ** & 95.39 & * & 19.44 & * \\
\hline$I_{5}=b_{5}+b_{124}+b_{136}$ & 2.73 & & 15.75 & & 0.99 & & 6.19 & \\
\hline$I_{6}=b_{6}+b_{234}+b_{135}$ & 71.44 & * & 2001.7 & $* * *$ & 205.46 & ** & 0.66 & \\
\hline$l_{12}=b_{12}+b_{45}$ & 1.63 & & 0.07 & & 1.93 & & 4.10 & \\
\hline$l_{13}=b_{13}+b_{56}$ & 1.50 & & 6.41 & & 1.95 & & 5.44 & \\
\hline$l_{14}=b_{14}+b_{25}$ & 6.52 & & 9.49 & & 0.38 & & 5.09 & \\
\hline$I_{23}=b_{23}+b_{46}$ & 0.01 & & 1.92 & & 4.70 & & 1.65 & \\
\hline$I_{24}=b_{24}+b_{15}+b_{36}$ & 4.84 & & 2.61 & & 15.14 & & 0.85 & \\
\hline$I_{34}=b_{34}+b_{26}$ & 7.42 & & 56.34 & * & 9.34 & & 0.00 & \\
\hline$l_{16}=b_{16}+b_{35}$ & 0.49 & & 0.71 & & 0.13 & & 0.34 & \\
\hline$I_{123}=b_{123}+b_{345}+b_{146}+b_{256}$ & 0.85 & & 3.88 & & 0.94 & & 0.24 & \\
\hline$l_{134}=b_{134}+b_{235}+b_{126}+b_{456}$ & 0.19 & & 0.04 & & 0.35 & & 0.05 & \\
\hline
\end{tabular}

a: $F$ cal. $=\left(S S_{j} / d d l_{j}\right) /\left(S S_{E} / d d l_{E}\right)$

b: $\left(^{*}\right) F_{0.05}^{\text {crit. }}(1,2)=18.51,\left({ }^{* *}\right) F_{0.01}^{\text {crit. }}(1,2)=98.49$ and $\left({ }^{* * *}\right) F_{0.001}^{\text {crit. }}(1,2)=998.50$

not necessary to write second order interaction models and to plot three-dimensional projection of the models to give a satisfactory description of the influence of the variables.

By a visual inspection of the responses in table III, it is immediately seen (without any calculations) that the sulfonation yields of benzene $\left(y_{B}\right)$ are low and their variations are not large (3 to $8 \%$ ). Therefore, no large effects of the variables on this response can be expected. It is also clear that the sulfonation yield of toluene and xylenes are high and vary in the same direction. Furthermore, it appears (Tab. IV) that one variable (the molar ratio) shows a very highly significant action on the sulfonation yields of toluene $\left(y_{T}\right)$ and xylenes $\left(y_{X}\right)$ and that four variables $(D, C, T$ and $E)$ show a relatively high influence on these two responses.

The estimates of the average $b_{0}$ vary between the threesulfonation yields. They decrease in the order $b_{0}$ (xylenes) $>$ $b_{0}$ (toluene) $>b_{0}$ (benzene). This agrees with the natural ranking of reactivity of these three aromatic hydrocarbons.
In the case of toluene sulfonation, among the confounded interaction effects, " $b_{34}+b_{26}$ " is significant. It is not possible to determine which of these confounded effects contributes to the slightly high value of the estimate. To be able to separate the confounded interaction effects, we should run a second $2_{\mathrm{IV}}^{6-2}$ fractional factorial design corresponding to the independent generators (5):

$$
I=1245=-2346 .
$$

In the absence of this complementary fraction design we can assume that $b_{26}$ (interaction between the concentration of the sulfonating agent and the molar ratio of sulfuric acid to toluene plus xylenes) is the dominating term since $X_{6}$ has the greatest effect on this response. But an interaction $\left(b_{34}\right)$ between temperature and azeotropic elimination of water is also plausible and expected. These data clearly indicate that these interaction effects tend to highly increase the sulfonation yield of toluene when reactions are carried out at high temperature with azeotropic elimination of water and/or with 
high concentration of the sulfonating agent and a high molar ratio.

Similar results are obtained for the xylenes sulfonation. In this case, however, $b_{3}$, " $b_{34}+b_{26}$ " and " $b_{24}+b_{15}+b_{36}$ " are only significant at the $90 \%$ confidence level when using an analysis of variance based on replicated experiments data (Tab. VI).

For the selectivity, the interpretation is also evident by mere regarding the estimated effects. They are rather small but two main effects $b_{2}(-1.97)$ and $b_{4}(0.88)$ are larger than the others. The signs of $b_{2}$ (negative) and $b_{4}$ (positive) indicate that selectivity would drop considerably when increasing the $\mathrm{SO}_{3}$ concentration of the sulfonating agent and/or when carrying out reactions without azeotropic elimination of water.

From the above analyses, the following conclusions can be drawn as to which experimental conditions should be used in the pilot plant experiment. These conditions would ensure maximum conversion of toluene and xylenes with minimum conversion of benzene:

- $X_{1}$ and $X_{3}$ : the reaction time and the temperature should be at their high level ( 9 hours and $110{ }^{\circ} \mathrm{C}$ ) since these factors don't affect the selectivity or benzene conversion but increase the sulfonation of toluene and xylenes.

- $X_{2}$ : the $\mathrm{SO}_{3}$ concentration of the sulfonating agent should be at a low level. However, it is not possible to use less than $97 \% \mathrm{H}_{2} \mathrm{SO}_{4}$ concentration since the global yield of the sulfonation could dramatically decrease. Crook and White [27] showed that with an initial concentration of sulfuric acid lower than $75 \%$, the sulfonation of toluene alone might not proceed.

- $X_{4}$ : sulfonation reactions should be carried out with azeotropic elimination of water to increase selectivity and global sulfonation of toluene and xylenes;

- $X_{5}$ : the time of addition of sulfonating agent is not critical. A short time is convenient (15 min);

- $X_{6}$ : the molar ratio of sulfuric acid to toluene plus xylenes should be at its low level to minimise the conversion of benzene.

These conditions are similar to those of experiment number 14 in the design. The product of this experiment designated by BTXS 14 is then selected to check its hydrotropic properties.

\section{Testing hydrotropic properties of BTXS 14}

The performance of BTXS 14 has been evaluated by comparing the effect of this blend on the clear point of a typical premium formulation of a concentrated liquid detergent (25\% dodecylbenzenesulfonate, $15 \%$ laurylethersulfate and $6 \%$ lauryldiethanolamide) [1] with that of STS or SXS, the most important hydrotrope in light duty liquids.

Tests show that in all cases, the use of BTXS 14 leads to a reduction in the viscosity and an improvement in the sta- bility of the concentrated detergent. Performances of the blend are between those of SXS and STS.

The clear points of the concentrated liquid detergent containing about $3 \%$ of the different hydrotropes are respectively: 29, 18 and, $10{ }^{\circ} \mathrm{C}$ for STS, BTXS 14 and SXS. The clear point of the detergent without hydrotrope is $45^{\circ} \mathrm{C}$. The addition of about $3 \%$ of pure SBS increases the clear point to $57{ }^{\circ} \mathrm{C}$.

Finally, it can be concluded that BTXS 14 can be used in concentrated liquid detergents to reduce their clear point but also to bring them into a desirable viscosity range.

\section{Conclusion}

The use of designed experiments and several analytical techniques allows us to choose suitable experimental conditions to carry out sulfonation of the BTX fraction of the Tunisian natural gas MISKAR in order to prepare hydrotropes for detergents. The product obtained using the proposed conditions show good hydrotropic properties when applied to concentrated liquid detergent. However, further studies carried out in a pilot plant are needed if the procedure is to be used in large production scale. An industrial plan seems to be very attractive since the by-product of the sulfonation reaction, the organic phase, has a similar composition than that of the BTX fraction of the natural gas and can thus be marketed as solvent.

\section{Acknowledgments}

The authors thank Professors Roger Phan-Tan-Luu, Michel Sergent and Didier Mathieu, Université Saint-Jérôme, LPRAI, Marseille (France), for giving us the software NEMROD and British Gas - Tunisia for supplying us the BTX fraction of the natural gas - MISKAR.

\section{References}

1. Drozd, J. C. Chem. Times Trends 1985, 8, 49-57.

2. Jakobi, G.; Löhr, A. Detergents and textile washing: principles and practice; VCH Publishers, (Henkel K - G.a.A.) 1987.

3. Agarwal, M.; Gaikar, V. G. Sep. Technol. 1992, 2, 79-88.

4. Mausner, M.; Katastra, R. D.; Spiegelman, G. US patent 1969, $3,458,449$.

5. Mausner, M.; Sosis, P. Soap and Chem. Spec. 1962, 38, 4750; 105-107.

6. Cerfontain H.; Kaandorp A. W.; Sixma F. L. J. Recl. Trav. Chim. 1960, 79, 935-936.

7. Vollbracht, L.; Cerfontain, H.; Sixma, F.L.J. Recl. Trav. Chim. 1961, 80, 11-19.

8. Cerfontain, H.; Sixma, F.L.J.; Vollbracht, L. Recl. Trav. Chim. 1963, 82, 659-670.

9. Cerfontain, H.; Sixma, F.L.J.; Vollbracht, L. Recl. Trav. Chim. 1964, 83, 226-232. 
10. Cerfontain, H. Recl. Trav. Chim. 1985, 104,153-165.

11. Bosscher, J. K.; Cerfontain, H. J. Chem. Soc. B 1968, 15241526.

12. Cerfontain, H. In: Mechanistic Aspects in Aromatic Sulfonation and Desulfonation; Interscience Publ., 1968.

13. Pisoni, C. EP patent 570 844, 1993.

14. Brooks, R.J.; Brooks, B. US patent 1966, 3, $240,801$.

15. Robin, M.; Schulte, S.R. US patent 1974, 3, 789, 067.

16. Arndt, O.; Mees, B. US patent 1980, 4, 242, 275.

17. El Homsi, A.; Guiglion, C.; Guiraud, R. Journal de Chimie Physique 1983, 80, 383-390.

18. El Homsi, A.; Gilot, B.; Canselier, J. P. J. Appl. Chem. Biotechnol. 1978, 28, 405-410.

19. Vandeginste, B.G.M. Anal. Chem. Acta 1983, 150, 199-206.

20. Box, E.P.; Hunter, W.G.; Hunter, J.S. Statistics for experimenters; New York: J. Wiley Ed. 1978.

21. Carlson, R. Design and optimisation in organic synthesis; Amsterdam: Elsevier Ed., 1992.
22. Montgomery, D.C. Design and analysis of experiments; New York: J. Wiley Ed., 1991.

23. Lewis, G.A.; Mathieu, D.; Phan-Tan-Luu, R. Pharmaceutical experimental design; New York: Marcel Dekker, Inc., 1999.

24. Goupy, J. La méthode des plans d'expériences; Paris: Dunod, 1988.

25. Mathieu, D.; Phan-Tan-Luu, R. Logiciel NEMROD. LPRAI, Marseille, 1999.

26. Daniel, C. Application of statistics to industrial experimentation; New York: Wiley, 1976.

27. Crook, M.; White, R. Chem. Eng. Prog. 1950, 46, 249-259.

28. Brendel, Mrs. L.; Gardos, G.; Redey, A. Hung. J. Ind. Chem. 1994, 22, 135-142.

29. Brendel, Mrs. L.; Gardos, G.; Redey, A. Chem. Tech. 1994, 46, 20-27.

30. Nakamoto, K. Infrared spectra of inorganic and coordination compounds, New York; Wiley Intersciences, 1970. 